\title{
Heat storage rate and acute fatigue in rats
}

L.O.C. Rodrigues,

A. Oliveira, N.R.V. Lima and C.A. Machado-Moreira
Laboratório de Fisiologia do Exercício, Escola de Educação Física, Universidade Federal de Minas Gerais, Belo Horizonte, MG, Brasil

\section{Correspondence}

L.O.C. Rodrigues

Laboratório de Fisiologia do

Exercício

Escola de Educação Física, UFMG

Av. Antônio Carlos, 6627

31270-901 Belo Horizonte, MG

Brasil

Fax: +31-3499-2325

E-mail: lor@eef.ufmg.br

Research supported by CAPES, CNPq, FAPEMIG and PRPq-UFMG.

Received May 5, 2002 Accepted September 30, 2002

\section{Abstract}

Thermal environmental stress can anticipate acute fatigue during exercise at a fixed intensity $\left(\% \mathrm{VO}_{2 \max }\right)$. Controversy exists about whether this anticipation is caused by the absolute internal temperature $\left(\mathrm{T}_{\text {int }},{ }^{\circ} \mathrm{C}\right)$, by the heat storage rate $(\mathrm{HSR}, \mathrm{cal} / \mathrm{min}$ ) or by both mechanisms. The aim of the present study was to study acute fatigue (total exercise time, TET) during thermal stress by determining $\mathrm{T}_{\text {int }}$ and HSR from abdominal temperature. Thermal environmental stress was controlled in an environmental chamber and determined as wet bulb globe temperature $\left({ }^{\circ} \mathrm{C}\right)$, with three environmental temperatures being studied: cold $\left(18^{\circ} \mathrm{C}\right)$, thermoneutral $\left(23.1^{\circ} \mathrm{C}\right)$ or hot $\left(29.4^{\circ} \mathrm{C}\right)$. Six untrained male Wistar rats weighing 260-360 g were used. The animals were submitted to exercise at the same time of day in the three environments and at two treadmill velocities (21 and $24 \mathrm{~m} / \mathrm{min}$ ) until exhaustion. After implantation of a temperature sensor and treadmill adaptation, the animals were submitted to a Latin square experimental design using a $2 \times 3$ factorial scheme (velocity and environment), with the level of significance set at $\mathrm{P}<0.05$. The results showed that the higher the velocity and the ambient temperature, the lower was the TET, with these two factors being independent. This result indicated that fatigue was independently affected by both the increase in exercise intensity and the thermal environmental stress. Fatigue developed at different $\mathrm{T}_{\text {int }}$ and HSR showed the best inverse relationship with TET. We conclude that HSR was the main anticipating factor of fatigue.
It has been well documented that the total exercise time (TET) is reduced in warmer environments and internal body temperature $\left(T_{\text {int }}\right)$ has been considered to be a limiting factor during prolonged physical exercise (1$5)$. This anticipation of fatigue seems to occur in order to prevent an increased $\mathrm{T}_{\text {int }}$ from compromising homeostasis. The mechanisms responsible for exercise interruption due to an increase in $T_{\text {int }}$ are still not well understood; controversy exists about whether there is a critical absolute $\mathrm{T}_{\text {int }}\left(\right.$ in ${ }^{\circ} \mathrm{C}$ ) or whether
Key words

- Thermoregulation

- Exercise

- Fatigue

- Heat storage rate the heat storage rate (HSR, in cal $/ \mathrm{min}$ ) is as important or even more important than $\mathrm{T}_{\text {int }}$ in the origin of fatigue.

Fuller et al. (6), studying the effect of warm environments on $T_{\text {int }}$ in rats during treadmill exercise, reported a shorter TET in animals exercising in warmer environments and similar abdominal and hypothalamic temperatures at the end of exercise at the time of fatigue, and suggested the existence of a critical absolute $\mathrm{T}_{\text {int }}$ which may lead to the interruption of activity. Walters et al. (7), 
studying exercising rats previously submitted to heat, showed that, in the heat, the higher the initial $\mathrm{T}_{\text {int }}$ the shorter the TET, with the hypothalamic and rectal temperatures at the end of exercise being similar at the time of fatigue. However, final $T_{\text {int }}$ was higher than that observed by Fuller et al. (6). Studies carried out on rats exercising at different intensities in an environment considered to be moderately cold for the animal $\left(22^{\circ}\right.$ to $\left.25^{\circ} \mathrm{C}\right)$ showed a $\mathrm{T}_{\text {int }}$ below $39^{\circ} \mathrm{C}$ at the time of fatigue $(8,9)$.

Another hypothesis that might explain the occurrence of fatigue is that a variation in body temperature as a function of time, i.e., HSR, plays an equal or even more important role than absolute $T_{\text {int }}$ itself. In a review on the endurance of rats, Hubbard and Armstrong (4) concluded that HSR, rather than the metabolic rate itself, was the determining factor of exercise capacity, with an inverse relationship being observed between HSR and endurance.

González-Alonso et al. (1), studying fatigue in humans during prolonged exercise in the heat, observed that TET was inversely proportional to initial $\mathrm{T}_{\mathrm{int}}$ and HSR and that fatigue developed at similar $\mathrm{T}_{\text {int }}$, thus reinforcing the hypothesis of the existence of a critical absolute $T_{\text {int }}$.

The above observations indicate the need for a better understanding of the effects of HSR on fatigue, since HSR is a dynamic variable that simultaneously considers the metabolic heat production rate during exercise (proportional to $\% \mathrm{VO}_{2 \max }$ ) and the degree of difficulty of heat dissipation to the environment (thermal stress). Therefore, the aim of the present study was to determine the effect of different HSR on fatigue and $\mathrm{T}_{\text {int }}$ in rats.

Six male Wistar rats weighing 260-360 g were used. The animals were maintained in collective cages in a room with a constant dry bulb temperature $\left(T_{D}\right)$ of $20 \pm 1^{\circ} \mathrm{C}$ under a 14- to 10-h light-dark cycle, with ration and water available ad libitum.

$\mathrm{T}_{\text {int }}$ was measured by implanting a tem- perature sensor (model TR3000XM-FM, Vital View Mini-Mitter, Sunriver, OR, USA) into the intraperitoneal cavity under ethyl ether anesthesia. An incision was made in the lumbar region of the animal, the peritoneal cavity was opened, the temperature sensor was inserted, and the peritoneum and skin were sutured. The sensor was calibrated with a precision of $0.01^{\circ} \mathrm{C}$. No healing abnormalities or alterations in weight gain of the animals were observed during the 5-day recovery period after surgery. After recovery, the animals were allowed to adapt to the treadmill exercise which consisted of running at a constant velocity of $15 \mathrm{~m} / \mathrm{min}$ with $0 \%$ inclination for $5 \mathrm{~min}$ per day, on 5 consecutive days at a constant ambient $T_{D}$ of 21 $\pm 1^{\circ} \mathrm{C}$. $\mathrm{T}_{\text {int }}$ was measured by telemetry every $30 \mathrm{~s}$ during rest, exercise and recovery. The following equation was used to determine the amount of heat stored during each experimental condition: $\operatorname{HSR}(\mathrm{cal} / \mathrm{min})=\left(\Delta \mathrm{T}_{\text {int }}\right) /$ $\mathrm{TET} \cdot \mathrm{g} \cdot \mathrm{c}$, where $\Delta \mathrm{T}_{\text {int }}$ corresponds to the total variation in $T_{\text {int }}$ between the beginning and end of exercise, $\mathrm{g}=$ weight of the animals, and $\mathrm{c}=$ specific heat body tissues $=0.82586$ cal g-1 ${ }^{\circ} \mathrm{C}^{-1}$.

During the experiments the animals were submitted to two velocities, i.e., 21 and 24 $\mathrm{m} / \mathrm{min}$, always at $0 \%$ inclination, on a Modular Treadmill for rats (Columbus Instruments International Corporation, Columbus, $\mathrm{OH}$, USA) until exhaustion, with exhaustion being defined as the time point when the animal was no longer able to maintain the preestablished velocity and needed to be stimulated with an electric shock $(0.5 \mathrm{mV}, 0.5$ $\mathrm{mA}$ ) (10). TET (in min) was defined as the time between the beginning of exercise and exhaustion. Different HSR were obtained by combining the treadmill velocities with three different ambient temperatures: cold $\left(18^{\circ} \mathrm{C}\right.$ wet bulb globe temperature, WBGT), thermoneutral $\left(23.1^{\circ} \mathrm{C}\right.$ WBGT $)$, or hot $\left(29.4^{\circ} \mathrm{C}\right.$ WBGT). WBGT was calculated from $\mathrm{T}_{\mathrm{D}}$ and the wet bulb $\left(\mathrm{T}_{\mathrm{W}}\right)$ temperature using the following equation for closed environments: 
WBGT $\left({ }^{\circ} \mathrm{C}\right)=0.3\left(\mathrm{~T}_{\mathrm{D}}\right)+0.7\left(\mathrm{~T}_{\mathrm{W}}\right)$.

At the end of the experiment, the animals were sacrificed with an ether overdose and no signs of infection or other type of internal anomaly were detected at autopsy.

The experimental design of the present study was of the Latin square type to avoid the training effect and the six experimental conditions were combinations of three ambient temperatures and two velocities. Each animal was submitted to the six experimental conditions at an interval of 4 days between each experiment in a crossed manner. Variables showing a normal distribution were analyzed by repeated measures analysis of variance, followed by correlations and regression curves, when appropriate. Differences between means were compared by the post hoc Student $t$-test, with the level of significance set at $5 \%$.

Figure 1A shows that the increase in treadmill velocity was accompanied by a reduction in the TET at the same ambient temperature $(21>24 \mathrm{~m} / \mathrm{min})$, and at the same velocity TET decreased with increasing ambient temperature (cold $>$ thermoneutral $>$ hot). On the other hand, TET showed no significant interaction between treadmill velocity and ambient temperature. These data indicate that fatigue was independently anticipated by both the increase in exercise intensity and thermal environmental stress.

Figure 1B shows that the increase in treadmill velocity was accompanied by an increase in HSR at the same ambient temperature $(24>21 \mathrm{~m} / \mathrm{min})$, except for the cold environment for which the difference was nonsignificant. Furthermore, HSR increased proportionally with increasing ambient temperature (hot $>$ thermoneutral $>$ cold) at the same velocity, and HSR behavior showed a significant interaction between treadmill velocity and ambient temperature $(\mathrm{P}<0.05)$. The data in Figure 1 indicate an inverse and symmetric correlation between mean TET and HSR, i.e., the higher the HSR the shorter the TET $(r=-0.762, \mathrm{P}<0.001)$.
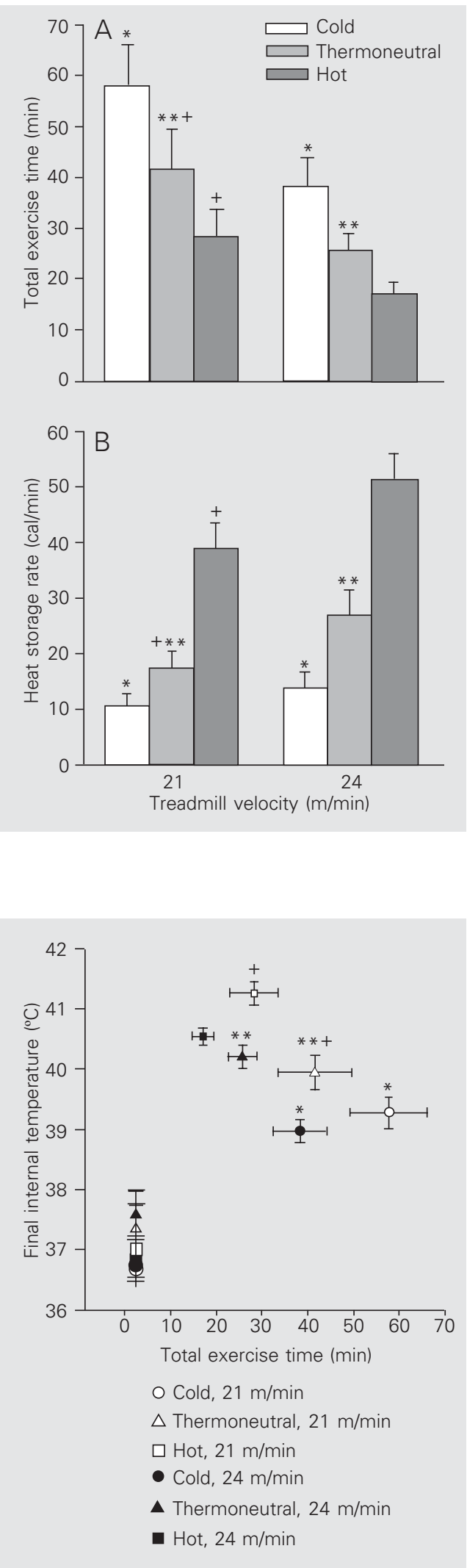

Figure 1. Total exercise time (A) and heat storage rate $(B)$ of untrained rats during treadmill exercise (21 or $24 \mathrm{~m} / \mathrm{min}$ ) in a cold $\left(18^{\circ} \mathrm{C}\right.$ wet bulb globe temperature, WBGT), thermoneutral $\left(23.1^{\circ} \mathrm{C}\right.$ WBGT) or hot $\left(29.4^{\circ} \mathrm{C}\right.$ WBGT) environment. Data are reported as means \pm SEM for 6 rats. ${ }^{*} \mathrm{P}<0.05$ compared to the thermoneutral and hot environments; ${ }^{*} \mathrm{P}<0.05$ compared to the hot environment; $+P<0.05$ compared to $24 \mathrm{~m} / \mathrm{min}$ in the same environment (Student $t$ test).

Figure 2. Final internal temperature of untrained rats during treadmill exercise (21 or 24 $\mathrm{m} / \mathrm{min})$ in a cold $\left(18^{\circ} \mathrm{C}\right.$ wet bulb globe temperature, WBGT) thermoneutral $\left(23.1^{\circ} \mathrm{C}\right.$ WBGT) or hot $\left(29.4^{\circ} \mathrm{C}\right.$ WBGT) environment. Data are reported as means \pm SEM for 6 rats. ${ }^{*} \mathrm{P}<0.05$ compared to the thermoneutral and hot environments; ${ }^{*} \mathrm{P}<0.05$ compared to the hot environment; ${ }^{+} \mathrm{P}<0.05$ compared to $24 \mathrm{~m} / \mathrm{min}$ in the same environment (Student $t$ test). 
As shown in Figure 2, a similar initial $\mathrm{T}_{\text {int }}$ of about $37.5^{\circ} \mathrm{C}$ was observed in all experimental situations. At the end of exercise, $T_{\text {int }}$ was higher than at the beginning of exercise. In addition, final $T_{\text {int }}$ differed between the various experimental situations studied, indicating that fatigue developed at different $\mathrm{T}_{\text {int }}$ for each experimental condition.

The present results show that fatigue developed proportionally to exercise intensity (treadmill velocity) and thermal environmental stress (WBGT). In addition, fatigue was inversely and significantly correlated with HSR, but the $T_{\text {int }}$ at the time of fatigue differed between the experimental situations studied. These findings disagree with the hypothesis that fatigue develops at a certain critical body temperature, but support the role of HSR in the development of fatigue.

Absolute $\mathrm{T}_{\text {int }}$ and HSR depend on the balance between metabolically produced heat and the rate of heat gain or loss to the environment. The thermal environment in which a minimal metabolic rate can be maintained during rest is defined as the thermoneutral environment, which, in rodents, ranges from $28^{\circ}$ to $32^{\circ} \mathrm{C}(11) . \mathrm{T}_{\text {int }}$ has been shown to be carefully regulated in rats submitted to high intensity exercise and/or warm environments due to their incapacity of heat dissipation through the saliva (12). $\mathrm{T}_{\text {int }}$ as a mechanism of fatigue is, therefore, potentiated during exercises performed in warm and humid environments.

Fuller et al. (6) studied the effect of different ambient temperatures $\left(23^{\circ}, 33^{\circ}\right.$ and $38^{\circ} \mathrm{C}$ with $40 \%$ relative humidity) on hypothalamic and abdominal temperatures in rats during treadmill exercise $(15 \mathrm{~m} / \mathrm{min}$ and $10 \%$ inclination) until fatigue. Walters et al. (7) also exercised rats on a treadmill $(17 \mathrm{~m} / \mathrm{min}$ and $8 \%$ inclination), with previous induction of different hypothalamic and rectal temperatures with microwaves. Both studies suggested the existence of a fatigue-critical $\mathrm{T}_{\text {int }}$, but the final temperature was approximately $2^{\circ} \mathrm{C}$ higher in one study (7) compared to the other (6).

Voluntary or central fatigue is considered to be a vital, complex, multifactorial and interactive phenomenon, which permanently integrates multiple sensory stimuli for the determination of a tolerable TET as a function of a fixed $\% \mathrm{VO}_{2 \max }(13)$. This sensory integration includes, among other factors, substrate availability, blood flow, oxygen flow, pulmonary ventilation and adequate neurohumoral activity, as well as the maintenance of acid-base, water-electrolyte and thermal equilibrium. According to this model, exercise interruption occurs before the occurrence of any disequilibrium in homeostasis which would compromise the integrity of the animal.

High tissue temperatures are known to induce structural and functional alterations in proteins involved in electrolyte transport through the cell membrane and sarcoplasmic reticulum, in actin-myosin interactions, and in mitochondrial respiration (14), changes that might lead to a reduction in physical performance, hyperthermia and/or even death $(1,10)$. Within this context, both absolute $T_{\text {int }}$ and HSR represent important indicators for the continuous assessment of the risk of homeostatic disequilibrium, and thus play a role in the mechanisms involved in acute fatigue.

Finally, it is interesting to note that in the present study the mean $\Delta \mathrm{T}_{\text {int }}$ observed under some experimental conditions $(0.20 \mathrm{cal} / \mathrm{min}$ at a velocity of $24 \mathrm{~m} / \mathrm{min}$ in the hot environment) was much higher than that observed for humans during exercise until fatigue in the heat $(3,15,16)$. This finding suggests that the differences in the thermoregulatory mechanisms between humans and rats, especially the capacity of sweating and the body surface/volume ratio, impair the extrapolation of data obtained in rats to the study of heat-related fatigue in humans.

HSR best correlated with acute fatigue during exercise performed in thermoneutral and hot environments at two intensities. 


\section{References}

1. González-Alonso J, Teller C, Andersen SL, Jensen FB, Hyldig T \& Nielsen B (1999). Influence of body temperature on the development of fatigue during prolonged exercise in the heat. Journal of Applied Physiology, 86: 1032-1039.

2. Gordon CJ (1993). Temperature Regulation in Laboratory Rodents. Cambridge University Press, New York, NY, USA.

3. Guimarães MT \& Silami-Garcia E (1993). Water replacement and thermoregulatory responses during prolonged exercise. Brazilian Journal of Medical and Biological Research, 26: 1237-1240.

4. Hubbard RW \& Armstrong LE (1986). The heat illnesses: biochemical, ultraestructural and fluid-electrolyte considerations. In: Pandolf KB, Sawka MN \& Gonzalez RR (Editors), Human Performance Physiology and Environmental Medicine at Terrestrial Extremes. Cooper Publishing Group, Carmel, IN, USA, 305-359.

5. Nielsen B, Strange S, Christensen NJ, Warberg J \& Saltin B (1997). Acute and adaptive responses in humans to exercise in a warm, humid environment. European Journal of Physiology, 434: 49-56.

6. Fuller A, Carter RN \& Mitchell D (1998). Brain and abdominal temperatures at fatigue in rats exercising in the heat. Journal of Applied Physiology, 84: 877-883.

7. Walters TJ, Ryan KL, Tate LM \& Mason PA (2000). Exercise in the heat is limited by a critical internal temperature. Journal of Applied Physiology, 89: 799-806.

8. Lima NRV (2000). Efeitos da injeção de metilatropina nos núcleos ventromediais do hipotálamo de ratos durante o exercício. Doctoral thesis, Programa de Pós Graduação em Ciências Biológicas, Instituto de Ciências Biológicas, UFMG, Belo Horizonte, MG, Brazil.

9. Rodrigues AG (2000). Efeito da estimulação colinérgica central nas alterações metabólicas de ratos não-treinados durante o repouso ou em exercício físico. Master's thesis, Programa de Pós Graduação em Ciências Biológicas, Instituto de Ciências Biológicas, UFMG, Belo Horizonte, MG, Brazil.

10. Hales JRS, Hubbard RW \& Gaffin SL (1996). Limitations of heat tolerance. In: Handbook of Physiology. Environmental Physiology. Vol. 1. Section 4, Chapter 15. American Physiological Society, Bethesda, MD, USA, 285-355.

11. Poole S \& Stephenson JD (1977). Body temperature regulation and thermoneutrality in rats. Quarterly Journal of Experimental Physiology, 62: 143-149.

12. Shellock FG \& Rubin SA (1984). Temperature regulation during treadmill exercise in the rat. Journal of Applied Physiology: Respiratory, Environmental and Exercise Physiology, 57: 1872-1877.

13. Gandevia SC (2001). Spinal and supraspinal factors in human muscle fatigue. Physiological Reviews, 81: 1725-1789.

14. Febbraio MA, Snow RJ, Stathis CG, Hargreaves M \& Carey MF (1994). Effect of heat stress on muscle energy metabolism during exercise. Journal of Applied Physiology, 77: 2827-2831.

15. Alves MNM, Ferrari-Auarek WM, Pinto KMC, Sá KR, Viveiros JP, Pereira HAA, Ribeiro AM \& Rodrigues LOC (1995). Effects of caffeine and tryptophan on rectal temperature, metabolism, total exercise time, rate of perceived exertion and heart rate. Brazilian Journal of Medical and Biological Research, 28: 705-709.

16. Moura MA, Rodrigues LOC, Waisberg Y, de Almeida HG \& SilamiGarcia E (2002). Effects of submaximal exercise with water ingestion on intraocular pressure in healthy human males. Brazilian Journal of Medical and Biological Research, 35: 121-125. 